\title{
Application and Verification of Multi-Model Products in Medium Range Forecast
}

\author{
Rong Yao' ${ }^{1}$, Zhiming Kang ${ }^{2}$, Yong $\mathrm{Li}^{3}$, Xiangning Cai ${ }^{3 *}$ \\ ${ }^{1}$ Hunan Meteorological Observatory, Changsha, China \\ ${ }^{2}$ Jiangsu Meteorological Observatory, Nanjing, China \\ ${ }^{3}$ National Meteorological Center of China Meteorological Administration, Beijing, China \\ Email: *cxn@cma.gov.cn
}

How to cite this paper: Yao, R., Kang, Z.M., Li, Y. and Cai, X.N. (2018) Application and Verification of Multi-Model Products in Medium Range Forecast. Journal of Geoscience and Environment Protection, 6, 178-193.

https://doi.org/10.4236/gep.2018.67012

Received: September 21, 2017

Accepted: July 28, 2018

Published: July 31, 2018

Copyright (C) 2018 by authors and Scientific Research Publishing Inc. This work is licensed under the Creative Commons Attribution International License (CC BY 4.0).

http://creativecommons.org/licenses/by/4.0/

\begin{abstract}
The verification analysis is applied to medium-range forecast products of T639, ECMWF, Japan model, NCEP ensemble forecast and NMC multi-model integration in late October 2012. The results show that ECMWF model has obvious advantage over other models in terms of height field and precipitation forecast; the westerly-wind index, geostrophic $U$ wind and 850 $\mathrm{hPa}$ temperature prediction products can reflect the adjustment of atmospheric circulation and the activity of cold air, which have a good reference for the medium-range temperature forecast in the eastern China; the prediction of ECMWF height field and wind field can well grasp the main weather processes within $192 \mathrm{~h}$, but beyond $192 \mathrm{~h}$ the model forecast ability decreases significantly; different models have large deviations in the medium-range forecast of typhoon track and the intensity and range of typhoon precipitation.
\end{abstract}

\section{Keywords}

Model, Verification, Medium-Range Forecast, Deviation

\section{Introduction}

China is a complex monsoon climate region, where disastrous weather distributes regionally, such as regional rainstorm, flood and drought, heat wave, dust storm, cold wave etc. So medium-range forecast is an important basis for decision-making and deployment of disaster prevention. The ability of medium-range forecast to predict large scale weather situation is more and more improved. But due to the inner complex of atmospheric motion and the limitations of numerical forecast model, there is still improving space in accuracy of medium-range forecast. In order to make good use of numerical models, we 
must first understand its performance, then re-process and extract more stable weather information, and finally use medium-range weather process analysis technology to make forecasts.

In this paper, the medium-range forecasting in late October 2012 is used to analyze the medium-range forecasting performance of the model products, to explore the medium-range forecasting difficulties and technology development direction. This is also an opportunity to introduce some medium-range forecast methods and products of medium-range platform used in National Meteorological Center of China.

\section{Model Forecast Products Verification}

\subsection{Real Weather}

In late October 2012, the temperature in Xinjiang and parts of Tibet was $1^{\circ} \mathrm{C}$ $2^{\circ} \mathrm{C}$ lower than normal, while in some other parts of China it was $2^{\circ} \mathrm{C}-4^{\circ} \mathrm{C}$ higher than normal, such as Huanghuai, Jiangnan, the eastern part of southwest China and the western part of South China; The precipitation in Jianghan, the northern part of Jiangnan and the southern part of South China was 50 - 100 $\mathrm{mm}$, while in local part of South China it was more than $200 \mathrm{~mm}$. In October 21-23, there was a snowstorm in the eastern part of northeast China; in October 24-27, a rainstorm appeared in the eastern part of southwest China and the Yangtze River; in October 28-29, another rainstorm appeared in South China.

\subsection{Verification of Different Model Forecast Products}

\subsubsection{Precipitation Verification}

At present, there are several precipitation forecast products (T639, ECMWF, Japan, NMC multi-model integrated precipitation forecast products) in NMC, and the ensemble forecast products have also been widely applied. Table 1 shows the comparison of different model precipitation forecasts and subjective forecast with observation. Among them, the model prediction refers to the use of a variety of forecasting products to forecast, and subjective forecast refers to the direct prediction by manual observation. It can be seen from Figure 1 that all the four deterministic models accurately predict the rain belt in the eastern part of the Northeast China. The ECMWF prediction is in accordance with the rain belt shape and precipitation level, the Japanese model is followed, while the T639 and the NMC Multi-model integrated forecast precipitation is slightly smaller. For the precipitation in central China, the ECMWF rainfall intensity in the northwest of Hunan is a little stronger than observation; the precipitation pattern of the Japanese model is similar to observation, but the position is slightly north. But the precipitation intensity of T639 model and the NMC Multi-model integrated forecast is slightly stronger and the range is north. For the heavy rainfall in South China, the precipitation intensity of the four models is obviously weaker and the range is obviously smaller. Only the T639 model predicts that there is more than $50 \mathrm{~mm}$ rainfall in Hainan, where ECMWF model predicts about $25 \mathrm{~mm}$, 

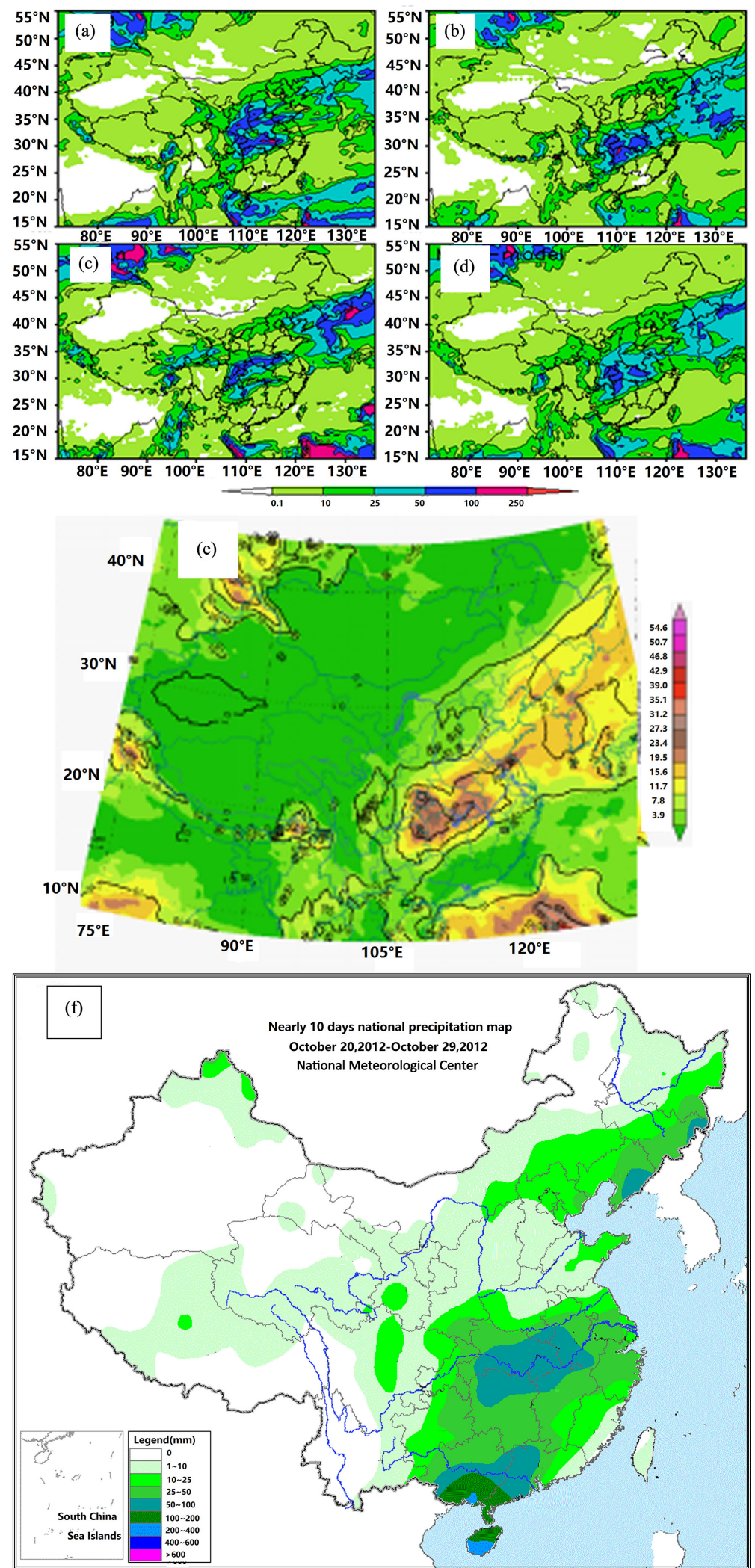

Figure 1. The cumulative precipitation of T639 (a); ECMWF (b); Japan (c); Multi-model integrated (d); ECMWF ensemble average forecast (e) and the observed precipitation (f) during 20-29 October 2012 (unit: mm). 
Table 1. Comparison of different model forecast and subjective forecast with the observed precipitation.

\begin{tabular}{|c|c|c|c|c|c|c|}
\hline $\begin{array}{l}\text { forecast } \\
\text { observation }\end{array}$ & T639 & ECMWF & Japan & $\begin{array}{l}\text { Multi-model } \\
\text { integrated }\end{array}$ & $\begin{array}{l}\text { ECMWF ensemble } \\
\text { forecast }\end{array}$ & Subjective Forecast \\
\hline $\begin{array}{l}\text { Precipitation in the } \\
\text { eastern part of the } \\
\text { Northeast China }\end{array}$ & $\begin{array}{l}\text { Basically } \\
\text { consistent, Local } \\
\text { precipitation } \\
\text { above } 50 \mathrm{~mm} \\
\text { omission }\end{array}$ & consistent & $\begin{array}{l}\text { Basically } \\
\text { consistent, } \\
\text { precipitation } \\
\text { range above } 50 \\
\mathrm{~mm} \text { is too large }\end{array}$ & $\begin{array}{l}\text { Basically } \\
\text { consistent, } \\
\text { Local } \\
\text { precipitation above } 50 \\
\text { mm omission }\end{array}$ & consistent & $\begin{array}{l}\text { Basically } \\
\text { consistent, Local } \\
\text { precipitation above } \\
50 \mathrm{~mm} \text { omission }\end{array}$ \\
\hline $\begin{array}{l}\text { Precipitation in the } \\
\text { eastern part of the } \\
\text { northwest and } \\
\text { southwest China, } \\
\text { Jianghuai, Jiangnan }\end{array}$ & $\begin{array}{l}\text { The rain belt is } \\
\text { obviously } \\
\text { northward }\end{array}$ & $\begin{array}{l}\text { The location of } \\
\text { rain belt is good, } \\
\text { while } \\
\text { precipitation in } \\
\text { Jiangnan forecasts } \\
\text { weaker }\end{array}$ & $\begin{array}{l}\text { The rain belt is } \\
\text { northward, and } \\
\text { the precipitation } \\
\text { center deviates } \\
\text { greatly }\end{array}$ & $\begin{array}{l}\text { Precipitation range } \\
\text { above } 25 \mathrm{~mm} \\
\text { forecasts northward }\end{array}$ & $\begin{array}{l}\text { The location of rain } \\
\text { belt is good, while } \\
\text { precipitation in } \\
\text { Jiangnan } \\
\text { forecasts weaker }\end{array}$ & $\begin{array}{l}\text { The rain belt is } \\
\text { northward and the } \\
\text { precipitation in } \\
\text { Huanghuai } \\
\text { forecasts too large }\end{array}$ \\
\hline $\begin{array}{l}\text { Precipitation in the } \\
\text { South China }\end{array}$ & Precipitation fore & casts obviously weake & & & & \\
\hline
\end{tabular}

and the multi-model integrated forecast is weaker. The Japanese model omits the precipitation in this region. In contrast, the precipitation forecasting effect of ECMWF model is superior. The average precipitation of ECMWF ensemble forecast has a good reference value for the rain belt in northeast China, and an omission of the rainfall in South China.

\subsubsection{Verification of Circulation System Forecast}

In order to verify the forecasting ability of each numerical forecast model for major weather processes in the medium-range forecast time, $500 \mathrm{hPa}$ height, 850 $\mathrm{hPa}$ wind and sea level pressure fields forecasted from 1200UTC October 20-28 by $\operatorname{ECMWF}\left(2.5^{\circ} \times 2.5^{\circ}\right)$, T639 $\left(1^{\circ} \times 1^{\circ}\right)$ and the Japanese $\left(2.5^{\circ} \times 2.5^{\circ}\right)$ model are compared with initial fields. The results (See Table 2) show that the three models have a certain ability in forecasting main influence systems of case 1 (blizzard in Northeast China on October 21-23) and case 2 (heavy rain in Jiangnan on October 24-26), but in comparison, the ECMWF model is closer to the initial field. For case 3 (rainstorm in South China on October 27-30), these models have some forecasting ability for the trough in $500 \mathrm{hPa}$ and the ground cold air, but little ability for the tropical system; the ECMWF and Japan model forecast the generation of tropical system with large path error, while T639 missed the prediction of the tropical system. The results also show that the forecasting ability of each model is weakened with the extension of forecasting time.

Taking into account that the ECMWF model has better prediction ability than other models, we focus on October 25-28 daily situation fields. It can be seen from daily ECMWF $500 \mathrm{hPa}$ height and $850 \mathrm{hPa}$ wind field superposition map (Figure 2) that the trough in Northwest China on October 25-26 moved eastward rapidly and affect the eastern part of Northwest China, North China and Northeast China; a small trough split from India-Burma trough influenced the eastern part of Southwest China and the Yangtze River; the water vapor from the 

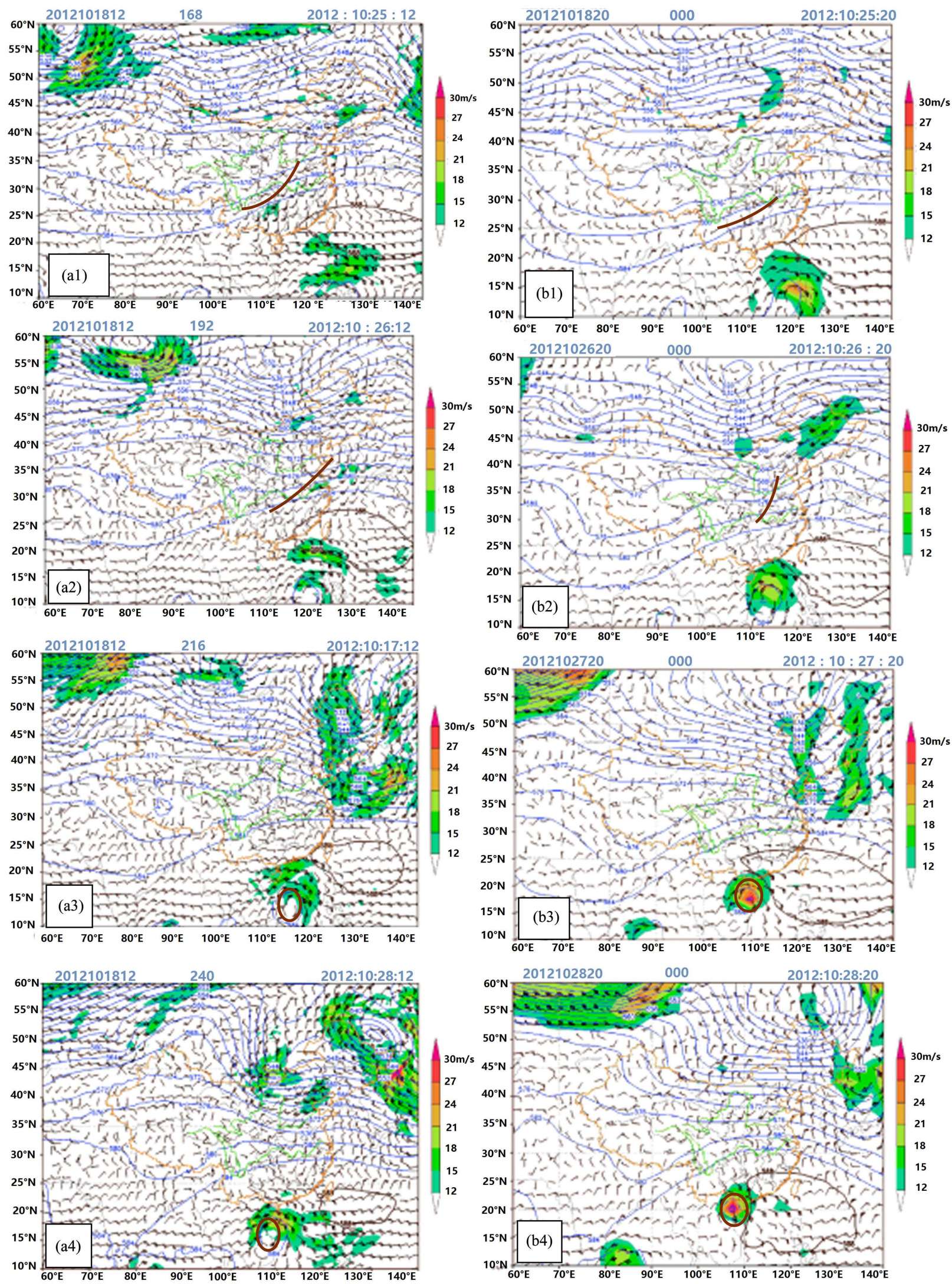

Figure 2. ECMWF $500 \mathrm{hPa}$ height and $850 \mathrm{hPa}$ wind field during October 25-28 (a1-4 prediction field, b1-4 analysis field). 
Table 2. Comparison of circulation system forecasted by different models with initial field.

\begin{tabular}{|c|c|c|c|}
\hline $\begin{array}{c}\text { forecast } \\
\text { initial field }\end{array}$ & T639 & ECMWF & Japan \\
\hline $\begin{array}{c}\text { Case 1: Blizzard in Northeast China } \\
\text { on October } 21-23 \text {, circulation system: } \\
\text { Trough in } 500 \mathrm{hPa} \text {, shear and cold } \\
\text { vortex in } 850 \mathrm{hPa}\end{array}$ & $\begin{array}{c}72 \text { - } 96 \text { h Forecast } \\
\text { (consistent) }\end{array}$ & $\begin{array}{c}72 \text { - } 96 \text { h Forecast } \\
\text { (consistent) }\end{array}$ & $\begin{array}{l}72 \text { - } 96 \text { h Forecast } \\
\text { (consistent) }\end{array}$ \\
\hline $\begin{array}{c}\text { Case 2: Heavy rain in Jiangnan on } \\
\text { October } 24-26 \text {, circulation system: } \\
\text { Trough in } 500 \mathrm{hPa} \text {, shear in } 850 \mathrm{hPa} \text {, } \\
\text { weak cold air }\end{array}$ & $\begin{array}{c}144-192 \mathrm{~h} \\
\text { Forecast (some } \\
\text { deviation) }\end{array}$ & $\begin{array}{c}144 \text { - } 192 \text { h Forecast } \\
\text { (consistent) }\end{array}$ & $\begin{array}{c}144 \text { - } 192 \text { h Forecast } \\
\text { (consistent) }\end{array}$ \\
\hline $\begin{array}{c}\text { Case 3: Rainstorm in South China on } \\
\text { October } 27-30 \text {, circulation system: } \\
\text { Trough in } 500 \mathrm{hPa} \text {, Typhoon inverted } \\
\text { trough, cold air }\end{array}$ & $\begin{array}{l}\text { large deviation in } \\
192-240 \mathrm{~h} \\
\text { typhoon forecast }\end{array}$ & $\begin{array}{c}\text { some deviation in } \\
192-240 \text { h typhoon } \\
\text { forecast }\end{array}$ & $\begin{array}{c}\text { some deviation in } \\
192 \mathrm{~h} \text { typhoon } \\
\text { forecast }\end{array}$ \\
\hline
\end{tabular}

South China Sea transported along the northwestern edge of subtropical high and collected in the Yangtze River. Due to the relatively stable subtropical high, $850 \mathrm{hPa}$ shear maintained here for 2 - 3 days. In addition, subtropical high moved eastward slowly during October 25-28 and there was a tropical system in the south side of subtropical high, which moved northwest and reached the ocean in the southwest of Hainan on October 28.

Compared with the analysis field, it was showed that ECMWF model can accurately predict the position of trough and shear in 192-hour, which reflected the evolution trend of the subtropical high and the activity of the tropical system. However, ECMWF model had a certain degree of deviation in the prediction of the trough and shear from 216-hour, especially in the shape of subtropical high and the location and intensity of the tropical system. ECMWF model forecasted weaker and more east subtropical high and weaker and more south tropical system than the initial field from 216-hour to 240-hour, and it did not forecast No. 23 typhoon "SON-TINH" in 2012 entered Guangxi after landing in Vietnam.

\subsubsection{Verification of the Average Height Field}

From the $500 \mathrm{hPa}$ average height field during October 20-28 forecasted by ECMWF model from 1200UTC October 18 (48 - $240 \mathrm{~h}$, the same below) (Figure $3(\mathrm{a})$ ), it can be seen that the polar vortex distributes around the north pole, the Eurasian westerly frontal zone affecting China locates in the northeastern region, the zonal subtropical high locates in the South China Sea and the east ocean of Taiwan, the northern boundary of subtropical high is near $25^{\circ} \mathrm{N}$, while India-Burma trough is so deep that the southwest airflow will affect the southern region. Compared with the initial $500 \mathrm{hPa}$ average height field during October 20-28 (Figure 3(b)), it is found that the ECMWF model is consistent with the initial field in terms of front position, the position and shape of the subtropical high and the forecast of trough. Similarly verifying the NCEP ensemble predic- 
tion (Figure 3(c)), it can be seen that the polar vortex is located more northerly, the westerly frontal zone is located near the Okhotsk Sea, and the meridian and location of the India-Burma trough are basically consistent with the initial field, but the subtropical high is more west and northerly.
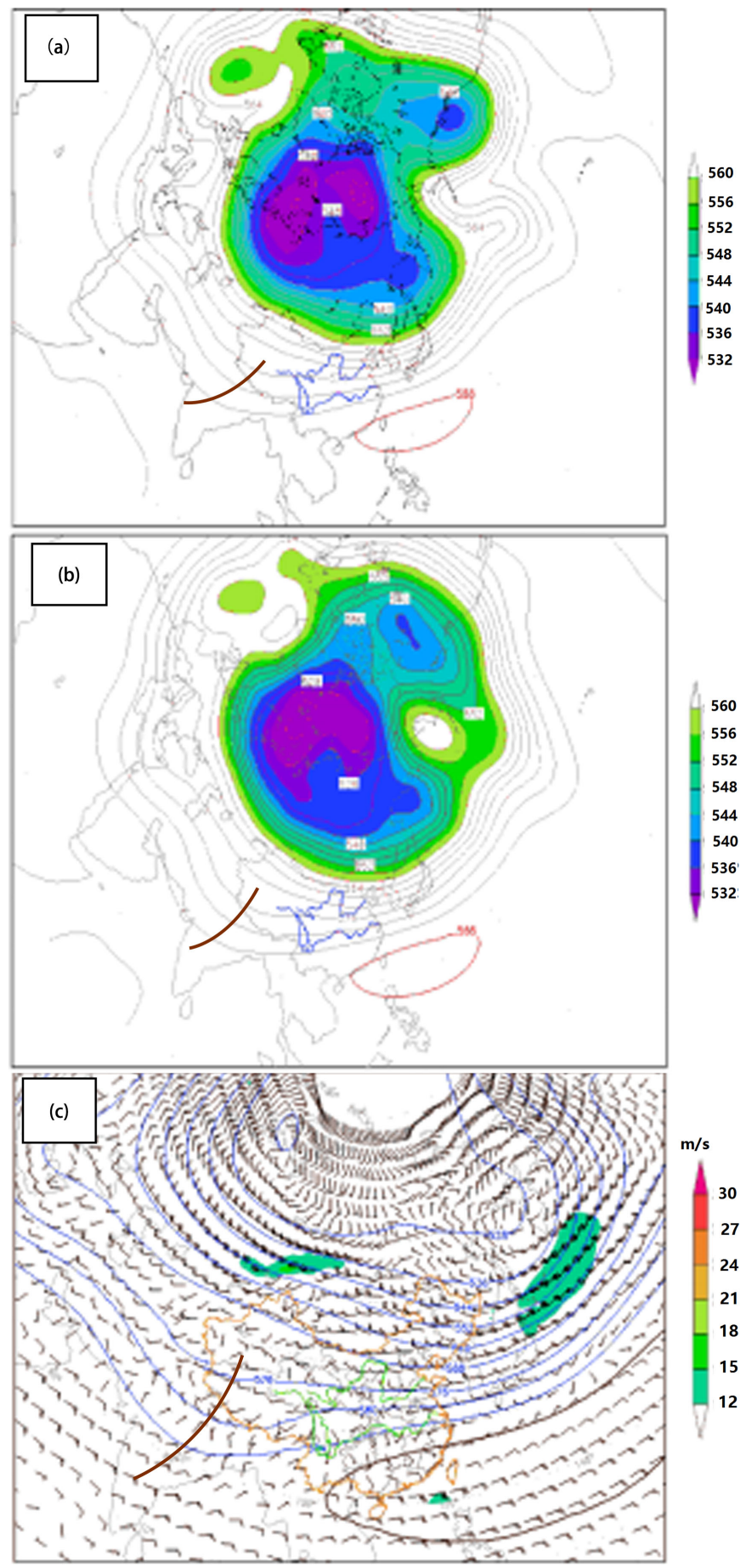

Figure 3. ECMWF $500 \mathrm{hPa}$ average height forecast field (a), zero field (b), NCEP ensemble forecast $500 \mathrm{hPa}$ average height and 850 hPa wind field (c) during October 20-28 (unit: dagpm). 


\subsubsection{Temperature Verification}

According to the statistical results of the National Climate Center and Meteorological Center of China, it is shown that the $850 \mathrm{hPa}$ temperature in the winter half is positively correlated with the surface temperature, which has a good reference for the surface temperature forecast [1] [2] [3] [4] [5]. From the $850 \mathrm{hPa}$ average temperature anomaly field during October 20-28 forecasted by ECMWF model from 1200UTC October 18 (Figure 4(a)), it can be found that most regions in China are positive anomalies besides the northern part of the Northeast China, which indicates that the temperature in most parts of China in the third dekad of October is higher than normals. Compared with the initial $850 \mathrm{hPa}$ temperature field during October 20-28 (Figure 4(b)), it is found that the forecast is in good agreement with the initial field.
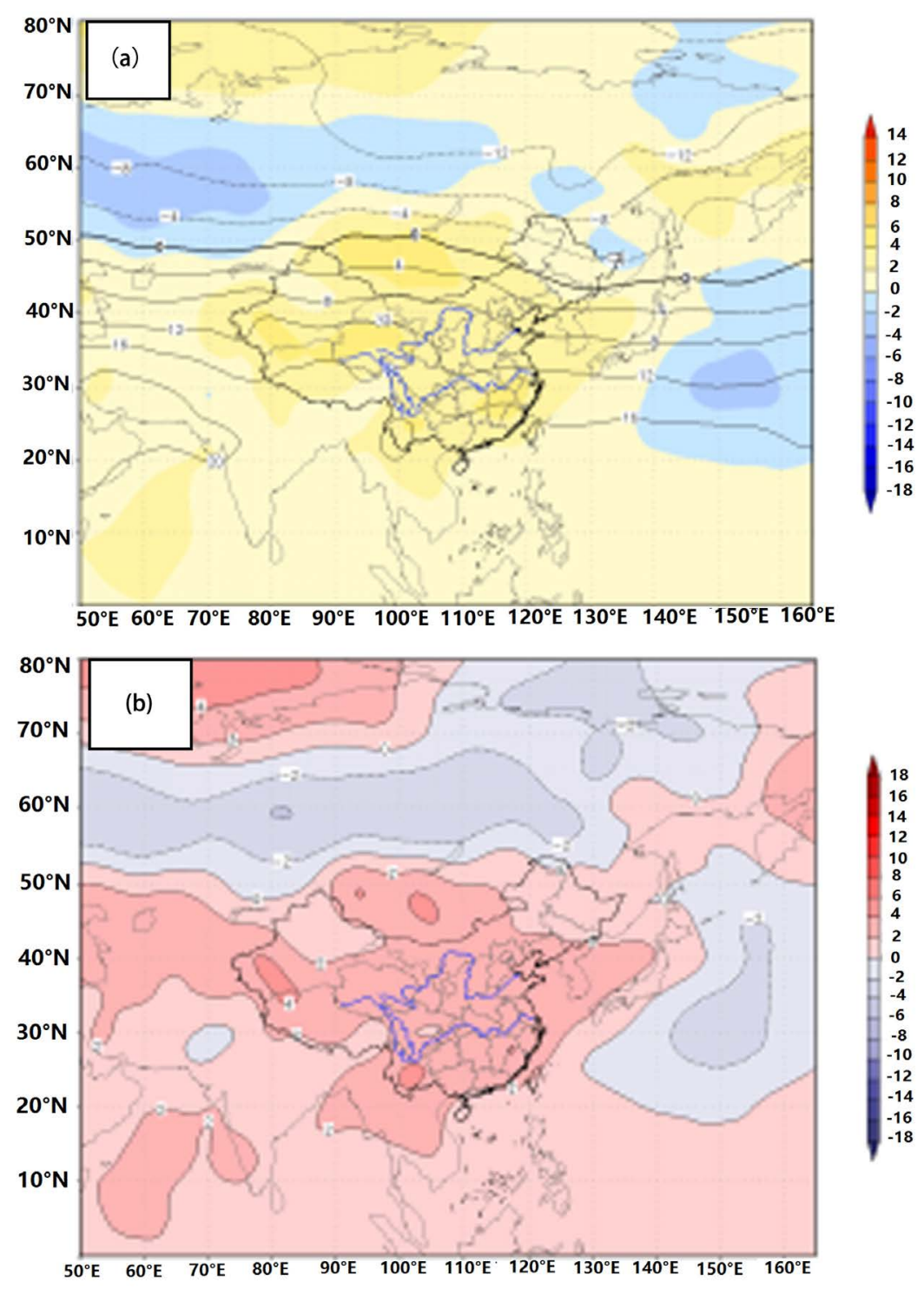

Figure 4. ECMWF $850 \mathrm{hPa}$ temperature anomaly prediction field (a) and analysis field (b) during October 20-28 (unit: ${ }^{\circ} \mathrm{C}$ ). 


\subsubsection{Westerly Index Verification}

The westerly index can not only reflect the adjustment of atmospheric circulation, but also reflect the intensity and change of cold air [6] [7] [8]. From the evolution of westerly index during October 20-28 forecasted by ECMWF model from 1200UTC October 18 (Figure 5(a)), it can be seen that the westerly index began to rise rapidly from October 20, then decline slightly only on October 24 and October 28. So it can be deduced that the atmospheric circulation will adjust from the meridional type to the zonal type. Although the westerly index is below the average, but the fluctuation is small, which indicates that the cold air is weak. Compared with the actual situation (Figure 5(b)), it can be found that on October 20 the atmospheric circulation began to change from the meridional type to the zonal type, which is consistent with the actual evolution. The westerly index forecast has some reference for judging the atmospheric circulation adjustment and forecasting the ground temperature trend.
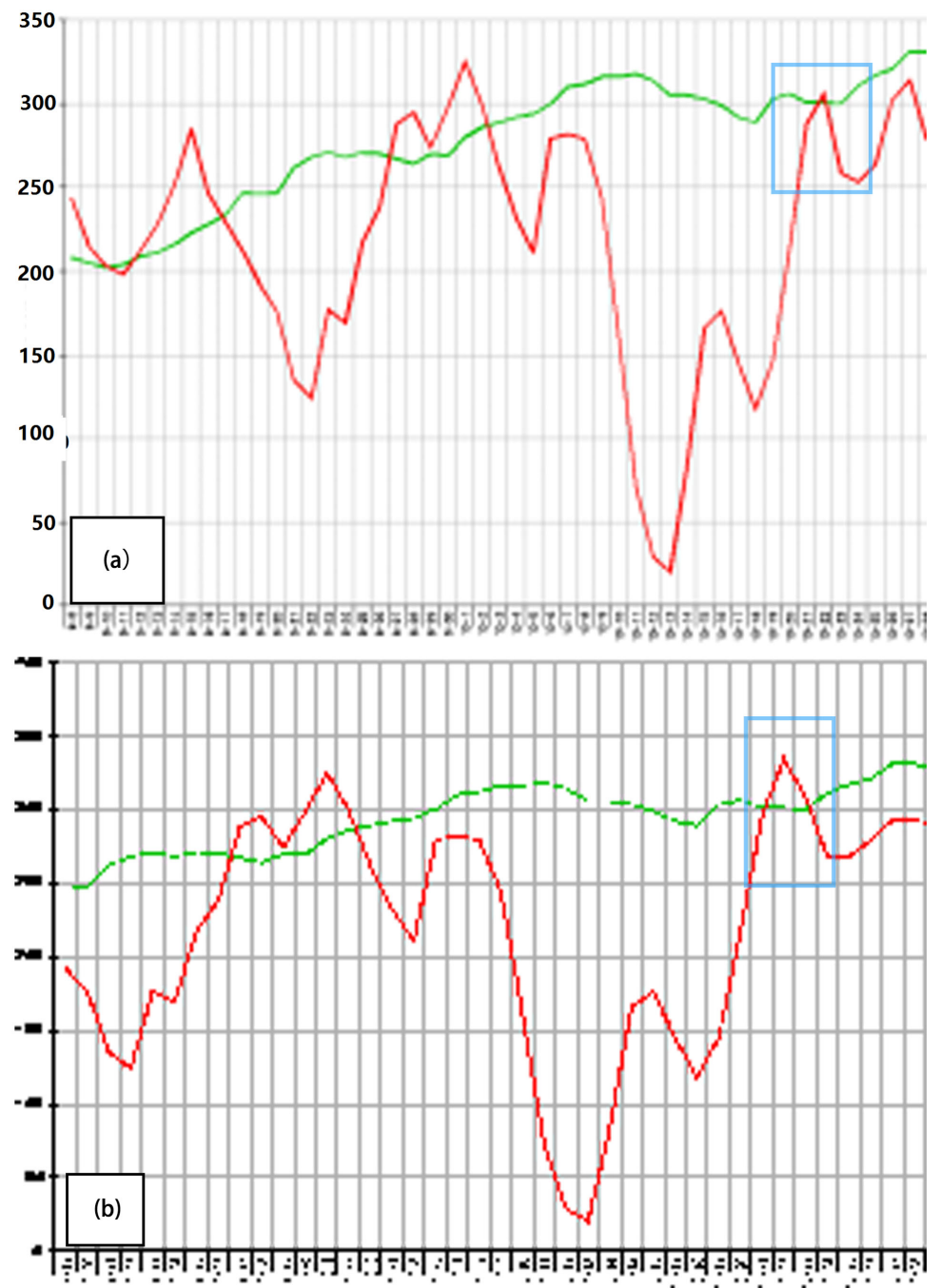

Figure 5. Westerly index forecast (a) (red solid line) and actual situation (b) (red dotted line) in late October (green line refers to the average situation). 
The analysis of various model forecast products show that ECMWF model has the best performance in forecasting precipitation process, dekad rainfall and the circulation. In addition, ECMWF $500 \mathrm{hPa}$ average height field forecast is more accurate for the atmospheric circulation and the main influence system, which can provide reference for mid-term forecast of precipitation trend; ECMWF 850 $\mathrm{hPa}$ temperature anomaly forecast ability is strong and the westerly index forecast is better, which have some reference value for dekad average temperature and cold air process forecast.

In addition, we can see from the figure that there is a difference between the index forecast and the actual situation. This is mainly due to the error in the index forecasting process and the fact that the forecast is very uncontrollable. Therefore, the index forecast and the actual situation will be different.

\section{Model Forecast Products Application}

\subsection{Precipitation Forecast}

In the dekad precipitation forecast, the model products can be used as the weather forecasting technology, which is based on the cumulative precipitation of deterministic models and ensemble forecast, dekad average height field and wind field, etc. However, there are significant differences in dekad precipitation between different seasons and regions. Whether the model's precipitation forecast is matched with the circulation and impact system forecast, which model has a better reference function, whether it is consistent with local climatic value and empirical index, all these problems need to be considered in the forecast of precipitation. From the circulation forecast of each model in late October 2012, it can be found that the northeast cold vortex and strong cold air might affect the Northeast China during October 21-23, with obviously water vapor convergence in the middle and low-level (Figure omitted). Combined with precipitation forecast products of four deterministic models, it can predict the strong rain belt in the eastern part of Northeast China. But mentioned the precipitation forecast in the central region of China, the four models are different in the rain area and intensity. In order to determine the rainfall position and the amount of precipitation, it should be focused on the $850 \mathrm{hPa}$ mean wind field and the position of the convergence zone and the forecast stability of the southwest jet and shear at $850 \mathrm{hPa}$ of ECMWF model and the precipitation products of ensemble forecast. As for the precipitation in South China, the precipitation forecasting products of each model are more different. It is predicted in the situation field that there will be a tropical system in late October in South China Sea, but the typhoon path and intensity are uncertain, which bring great difficulty for precipitation forecast in South China and need to focus on research in the future medium-range forecast (Figure 6).

\subsection{Temperature Anomaly Forecast}

At present, for the prediction of temperature anomaly, the main products for 

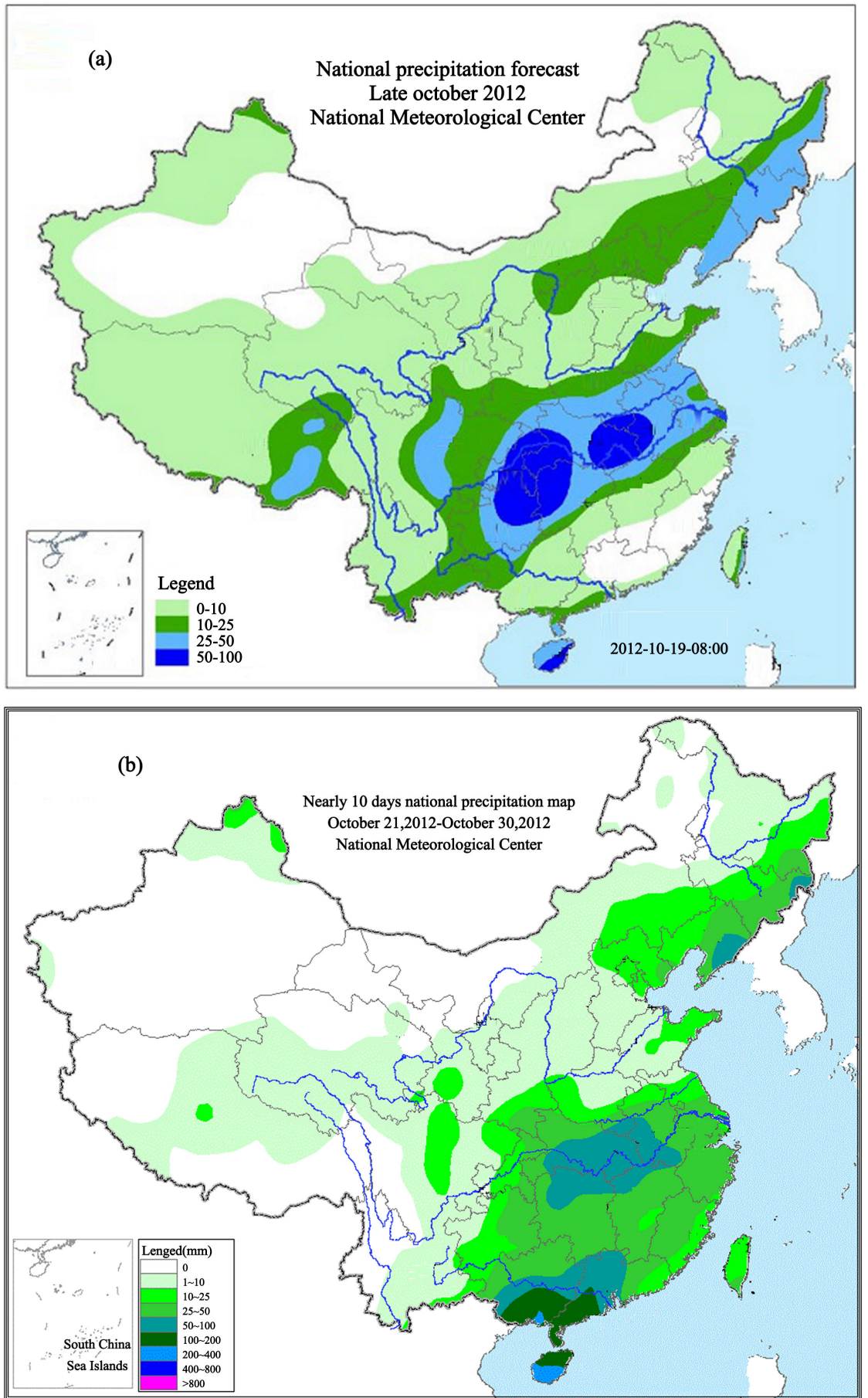

Figure 6. Forecast (a) and actual (b) precipitation in late October (unit: $\mathrm{mm}$ ).

reference are $850 \mathrm{hPa}$ temperature anomaly, daily $850 \mathrm{hPa}$ temperature, westerly index, $500 \mathrm{hPa}$ average geostrophic wind and so on. The previous tests show that $850 \mathrm{hPa}$ temperature anomaly in late October forecasted by ECMWF model is consistent with the observation, that is most parts of China have higher temperature than normal besides the northern part of Northeast China. Meanwhile 500 $\mathrm{hPa}$ average geostrophic $\mathrm{U}$ wind shows that (Figure omitted), the main location 
of the frontal area is east, and the evolution of westerly index reflects that the atmospheric circulation will be adjusted to zonal circulation, indicating that the cold air is weak with small influence on China. In addition, the subtropical high controls Jiangnan and South China in the late period of October, so the temperature in most areas will have a higher trend. Comparing mean temperature anomaly forecast with the observation (Figure 7), it can be found that the main deviations are located in Xinjiang and Tibet. As the temperature in western region does not have a good correspondence with $850 \mathrm{hPa}$ temperature, it is worthy of further analysis and research how to accurately predict the temperature trend in the western region.
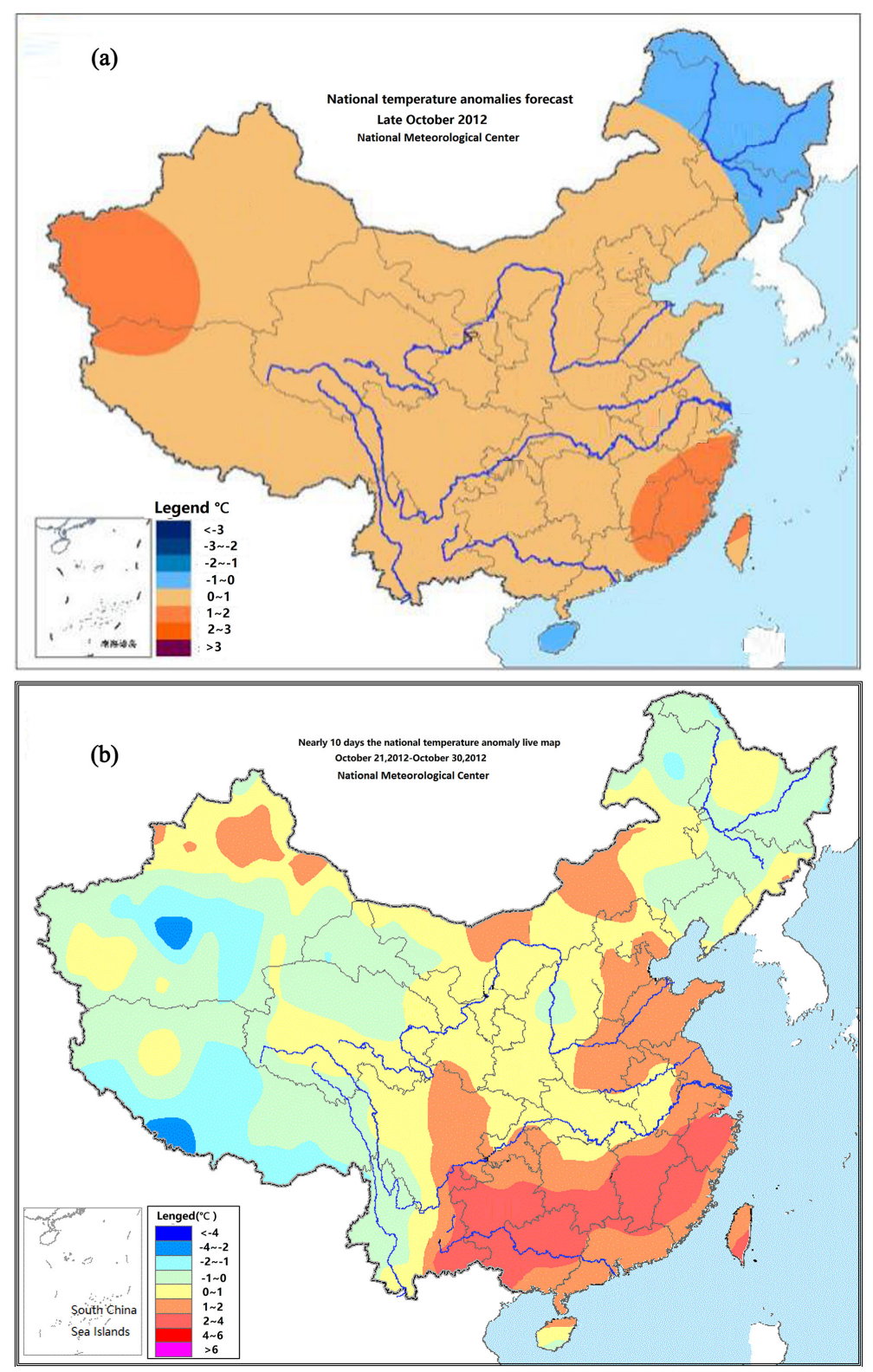

Figure 7. The subjective forecast (a) and observation (b) of ground temperature anomalies in late October (unit: ${ }^{\circ} \mathrm{C}$ ). 


\subsection{Main Process Forecast}

The main process forecast in the late October should focus on heavy rainfall (rain or snow) period and intensity, the impact period of cold air, cooling amplitude, precipitation phase change, etc. Based on the analysis of the $500 \mathrm{hPa}$ geopotential height field, $850 \mathrm{hPa}$ wind field and precipitation forecasting products of ECMWF, T639 and other models, the main precipitation process period, area and strength can be determined with water vapor, dynamic and unstable energy conditions. By analyzing daily pressure field, $850 \mathrm{hPa}$ temperature field and declining stage of westerly index forecasted by several models, the impact period of cold air and the temperature dropping amplitude can be determined. By analyzing daily $0^{\circ} \mathrm{C}$ and $-4^{\circ} \mathrm{C}$ line position on $850 \mathrm{hPa}$ temperature field, ground $2 \mathrm{~m}$ temperature forecasted by several models, precipitation phase can be judged with single station profile timing diagram and temperature threshold index. Based on the above analysis, it is concluded that there will be a strong cooling and blizzard process in Northeast China affected by northeast cold vortex from 21 to 23 October and a continuous heavy rainfall process from 24 to 27 October in the eastern part of Southwest China and the Yangtze River at the edge of subtropical high, which is consistent with the actual situation. While the forecast of strong precipitation in Hainan affected by tropical systems at about 28 October is too small in area and weak in intensity. The process happened in the late period of forecasting time is another challenge for mid-term forecaster. With the extension of forecasting time, the forecasting ability of each model is correspondingly weakened. For example, the forecast has a large deviation from the initial field about tropical system and subtropical high in the late October. In addition, after the weakened "SON-TINH" reaching Guangxi, the eastern section of the inverted trough combined with cold air in Guangdong, resulting in a large range of heavy precipitation in South China.

Through the above analysis, we may present some focus points about how to forecast precipitation, temperature and main processes in mid-term range: 1) Understand the climatic values in different areas and different seasons, master the seasonal variation characteristics of rain belt in China and the corresponding atmospheric circulation types, establish the forecasting experience index and conceptual model of relevant areas. 2) The total precipitation forecast is mainly based on the rainfall forecast of ECMWF model and precipitation products of other deterministic models and ensemble models; in combination with the 500 $\mathrm{hPa}$ average height field and the $850 \mathrm{hPa}$ low trough, shear and southwest jet. At the same time, the position and intensity of the rain belt can be corrected according to the position and intensity of the water vapor convergence center. 3) The prediction of temperature anomaly is mainly based on ECMWF $850 \mathrm{hPa}$ temperature and ground pressure field forecast. When the $850 \mathrm{hPa}$ temperature anomaly in the eastern part of China is positive, it is concerned whether there is cold air on the ground. If the cold air is weak, and $500 \mathrm{hPa}$ is controlled by the subtropical high or high pressure circulation for a long time, then the tempera- 
ture anomaly is predicted to be positive. When the $850 \mathrm{hPa}$ temperature anomaly is negative, the ground pressure field forecast shows that the cold air activity is frequent or the cold air force is strong, and the westerly index is obviously lower than normal, then the ground temperature anomaly is predicted to be negative. In the western region of China, due to the high altitude, $850 \mathrm{hPa}$ temperature anomaly cannot reflect the ground temperature anomaly. So we should refer to the $500 \mathrm{hPa}$ average height anomaly, the trough/ridge activity and the local temperature forecasting experience index. 4) Precipitation phase prediction should focus on the position change of $850 \mathrm{hPa} 0^{\circ} \mathrm{C}$ and $-4^{\circ} \mathrm{C}$ line, ground $2 \mathrm{~m}$ $0^{\circ} \mathrm{C}$ line and the cold air strength in ground pressure field of ensemble forecast. When the precipitation is predicted, the temperature in the whole troposphere is lower than $0^{\circ} \mathrm{C}$, there is high possibility of solid precipitation such as sleet and snow. When the lower layer temperature is higher than $0^{\circ} \mathrm{C}$, the liquid precipitation occurs. And when the warm and humid air flow is strong in the middle layer and there is inversion above the deep cold pad in the lower layer, there may be frozen weather. In addition, it is possible to judge the precipitation phase and distinguish the rain and snow process by the model precipitation phase prediction products combining with the temperature prediction of each layer and the local precipitation phase temperature index.

\section{Summary and Discussion}

\subsection{Summary}

In this paper, the verification analysis is applied to medium-range forecast products of T639, ECMWF, Japan model, NCEP ensemble forecast and NMC multi-model integration in late October 2012. At the same time, the deviation analysis between forecast and observation is carried out and focus points in medium-range forecast are proposed. The main conclusions are as follows:

1) Through the verification and analysis of medium-range precipitation forecast products of ECMWF, T639, Japan and multi-model integration, it can be found that ECMWF model is better than other models, not only can it accurately describe the strong rain belt in the southern region of the Northeast China, but also has a good forecasting ability for the location and intensity of the rain belt along the Yangtze River, which has a good reference effect on the medium-range precipitation forecast.

2) There are large deviations in the prediction of typhoon precipitation of each model. The forecast error of $500 \mathrm{hPa}$ height field and $850 \mathrm{hPa}$ wind field increase obviously from $216 \mathrm{~h}$ of ECMWF model. And there are also large deviations in the prediction of tropical system weakened into Guangxi, resulting in an underestimate precipitation generated by the westerly system combined with the tropical system in South China.

3) The temperature anomalies of $850 \mathrm{hPa}$ in late October have good correlation with the ground temperature in the eastern part of China, which has a good indication for the ground temperature anomalies in medium range forecast. 
However, there is a negative correlation between the temperature anomalies of $850 \mathrm{hPa}$ and the ground temperature in the western part of China. So the prediction of ground temperature anomalies in the western region cannot completely depend on the $850 \mathrm{hPa}$ temperature anomaly forecast.

4) When there is a big difference between circulation and the location of rain belt in deterministic forecast, the ensemble forecast can be an important technical supplement, which can provide credibility of the predictability for predictors as an important reference.

\subsection{Discussion}

It is a difficult and long-term task to improve the accuracy of medium-range forecast by making full use of and playing its guiding role under the premise of abundant domestic and foreign model products. Based on the verification of a variety of model products in medium-range, there is a good forecasting ability for the westerly system and main rain zone and process, but it is weak for the medium-range typhoon path and its impact forecasting ability. When models are quite different from the typhoon path and precipitation forecast, ensemble forecast is an effective means to solve the divergences [9], which is very important to improve the accuracy of typhoon path forecasting. The temperature anomaly of $850 \mathrm{hPa}$ in winter can be used as an important reference for predicting the ground temperature in the eastern part of China. However, the correlation is poor in the western part of China, which may be related to the altitude near the Qinghai-Tibet Plateau. At this time, it is necessary not only to pay attention to $850 \mathrm{hPa}$ temperature anomaly, but also focus on $500 \mathrm{hPa}$ height anomaly, which may provide some references for accurate prediction of ground temperature anomaly.

This paper finds through verification that different modes have their own advantages for different forecasting projects. For example, the ECMWF model has obvious advantages in height field and precipitation forecasting; the westerly index, U-turn and $850 \mathrm{hPa}$ temperature forecast products can reflect the adjustment of general circulation and cold air activities, and have a good prediction of mid-term temperature in eastern China. The predictions of ECMWF geopotential height field and wind field can well grasp the major weather processes within 192 hours, but the ability of pattern forecasting obviously drops after 192 hours. In addition, the different models are applied to forecast the intensity and range of the typhoon precipitation intensity and range, there is a big deviation.

\section{Funding}

This work was funded by 2015 Key Technological Integration Project of China Meteorological Administration (CMAGJ2015M40) and National Science and Technology Support Program (2015BAC03B04, 2015BAC03B06, 2015BAC03B07) of China. 


\section{References}

[1] Zhang, Y.N. and Zhang, J.Y. (2011) The Performance Verification of Medium-Range Forecast for T639 and ECMWF and Japan Models from Dec. 2010 to Feb. 2011. Meteorological Monthly, 37, 633-638.

[2] Jiang, X. and Cai, X.N. (2011) The Performance Verification of the Medium-Range Forecasting for T639 and ECMWF and Japan Model from June to August 2011. Meteorological Monthly, 37, 1448-1452.

[3] Zhou, N.F. (2011) Performance Verification of the Medium-Range Forecasting for T639, ECMWF and Japan Models from September to November in 2010. Meteorological Monthly, 37, 237-241.

[4] Cai, X.N. (2010) Performance Verification of the Medium-Range Forecasting for T639, ECMWF and Japan Models from September to November 2009. Meteorological Monthly, 36, 130-135.

[5] Zhang, T. (2009) The Performance Verification of Medium-Range Forecasting for T639 and ECMWF and JAPAN Model from September to November 2008. Meteorological Monthly, 35, 112-119.

[6] Rao, X.Q. (2008) Verification of Medium-Range Forecasting Efficiency of T213 and ECMWF and Japan Model from September to November 2007. Meteorological Monthly, 34, 107-114.

[7] Cai, X.N. (2011) Performance Verification of the Medium-Range Forecasting for T639, ECMWF and Japan Models from March to May 2011. Meteorological Monthly, 37, 1026-1030.

[8] Wang, Y. (2012) The Performance Verification of the Medium-Range Forecasting for T639 and ECMWF and Japan Models from December 2011 to February 2012. Meteorological Monthly, 38, 629-634.

[9] Xu, Y.L., Han, G.R., et al. (2011) The Analysis and Discussion on Operational Forecast Errors of Super Typhoon Muifa (1109). Meteorological Monthly, 37, 1196-1205. 